\title{
Long term urinary prognosis of cervical cord injury patients
}

\author{
$\mathrm{H}$ Morita MD, ${ }^{1}$ A Sazawa MD, ${ }^{2} \mathrm{~T}$ Kanno MD ${ }^{2} \mathrm{~T}$ Koyanagi $\mathrm{MD}^{2}$ \\ ${ }^{1}$ Department of Urology, Bibai Rousai Hospital, Hokkaido, Japan; ${ }^{2}$ Department of \\ Urology, Hokkaido University School of Medicine, Hokkaido, Japan.
}

\begin{abstract}
We made a retrospective comparative study of 88 cervical cord injury patients concerning their long term urological prognosis. In all, 129 urinary complications have occurred in 54 cases $(61.4 \%)$. The incidence of urinary complications was high in those with higher levels of injury (except $\mathrm{C} \sim 4$ lesions), a complete injury, a younger age of onset and a longer period after injury. Patients who had an indwelling catheter and a suprapubic cystostomy showed a higher rate of urinary complications. Urodynamically, there was no significant difference between the presence and absence of detrusor hyperreflexia. Those with detrusor-sphincter dyssynergia (DSD) also showed no difference compared to those without DSD. For the prevention of urinary complications in cervical cord injury patients, proper urinary management with clean intermittent catheterisation (CIC), or low pressure voiding is necessary in the early period after the onset of the injury.
\end{abstract}

Keywords: cervical spinal injury, urinary complications; urinary prognosis.

\section{Introduction}

Although the management of spinal cord injury had been improved, cervical cord injury patients still have more difficulties in many physical activities than do those with injuries of other spinal cord levels. Urologically in these cases, CIC sometimes cannot be indicated because of tetraplegia and poor activities of daily living (ADL). The aim of this study is to determine which factor is risky for long term prognosis of cervical SCI patients concerning their urinary tract and how we should conduct their urinary management.

\section{Patients and methods}

There was a total of 88 cervical cord injured patients with a mean age of 40.2 yrs (23-80 yrs). The mean period after injury was 11.6 yrs $(2-36 \mathrm{yrs})$. The distribution of injury levels and degrees of injury can be seen in Table I. Their urinary management and periodical follow ups had been done in at the urology department of Bibai Rousai
Table I Clinical features of patients

\begin{tabular}{lcc}
\hline Levels of injury & Complete & Incomplete \\
\hline C $\sim 4$ & 7 & 5 \\
C5 & 23 & 2 \\
C6 & 19 & 9 \\
C7 & 8 & 1 \\
Unknown & 3 & 11 \\
Total & 60 & 28 \\
\hline
\end{tabular}

Male:Female $=84: 4$

Age: $23-80$ yrs (mean age 40.2 yrs)

Period after injury: 2-36 yrs (mean period $11.6 \mathrm{yrs})$

Hospital. We made a retrospective comparative study of the patients based on the relationships between the urinary complications and some factors including age of onset, duration of illness, injury levels, degrees of injury, urinary management and urodynamic findings. Furthermore, we divided the patients into three groups according to the number of urinary complications. Group I had no urinary complications; 
group II had one-two complications; and group III had more than three complications. We also evaluated their differences in background, which might have influenced the urinary complications. A statistical examination was done by Student's $t$ test.

\section{Results}

There were 129 urinary complications during the clinical study (Table II). Lower urinary stones were the most frequent complication and symptomatic urinary infections followed. Chronic renal failure, upper urinary stones, epididymitis, and hydronephrosis were relatively late urinary complications, whereas vesicoureteral refluxes, urethral diverticula, urethral strictures, urethrocutaneous fistula, and prostatic abscesses occurred in the early period after onset.

The incidences of urinary complications of $\mathrm{C} \sim 4$ and $\mathrm{C} 7$ levels were relatively lower than those of C5 and C6 (Fig 1). Also, the incidence of urinary complications in cases with a complete lesion was significantly higher than those with an incomplete lesion $(p<0.05)$. The subjects were divided into five groups according to the age of onset: younger than 29 years; $30-39$ years; $40-49$ years; $50-59$ years; and older than 60 years (Fig 2). The group younger than 29 years showed a significantly high incidence of urinary complications as compared to other groups $(p<0.05$ or $p<0.01)$.
The rate of occurrence of urinary complications was higher in those with a longer period after injury. There was a significant difference $(p<0.05)$ between the group with a duration shorter than 5 years and the groups with a duration longer than 11 years (Fig 3).

Concerning urinary management, patients using CIC showed the lowest incidence of urinary complications $(53.8 \%)$, those who were self voiding were second $(58.1 \%)$, those with a suprapubic cystostomy were third $(61.2 \%)$, and the group with an indwelling catheter showed the highest rate of urinary complications $(75.0 \%)$ (Fig 4).

Urodynamically, there were 52 patients with detrusor hyperreflexia and 24 without (cystometry was done for 76 cases). In the cases with detrusor hyperreflexia, 29 $(55.8 \%)$ had experienced urinary complications, whereas 15 of $24(62.5 \%)$ showed urinary complications in those without detrusor hyperreflexia. There was no significant difference between the two groups. On electromyography of the external urethral sphincter, DSD was shown in 51 of 59 cases examined. The incidence of urinary complications in the patients with DSD was $26.9 \%$, and that in the cases without DSD was $50.0 \%$. There was also no significant difference between these two groups (Fig 5).

We evaluated the backgrounds of the three groups and divided the groups according to the number of complications (Table

Table II Urinary complications

\begin{tabular}{|c|c|c|}
\hline Urinary complications & $\begin{array}{l}\text { No. of complications } \\
\text { (No. of cases) }\end{array}$ & $\begin{array}{c}\text { Mean period from injury } \\
(\mathrm{yrs})\end{array}$ \\
\hline Lower urinary stone & $40(24)$ & 4.1 \\
\hline Urinary tract infection & $33(23)$ & 5.6 \\
\hline Upper urinary stone & $15(13)$ & 10.4 \\
\hline Epididymitis & $13(11)$ & 8.7 \\
\hline Vesicoureteral reflux & $11(11)$ & 1.4 \\
\hline Hydronephrosis & $6 \quad(6)$ & 7.5 \\
\hline Urethral diverticulum & 4 (4) & 1.0 \\
\hline Chronic renal failure & $3 \quad(3)$ & 26.3 \\
\hline Urethral stricture & 1 & 1.0 \\
\hline Urethrocutaneous fistula & 1 & 1.0 \\
\hline Perirenal abscess & 1 (1) & 7.0 \\
\hline Prostatic abscess & 1 (1) & 1.0 \\
\hline Total & $129(54 / 88)$ & \\
\hline
\end{tabular}




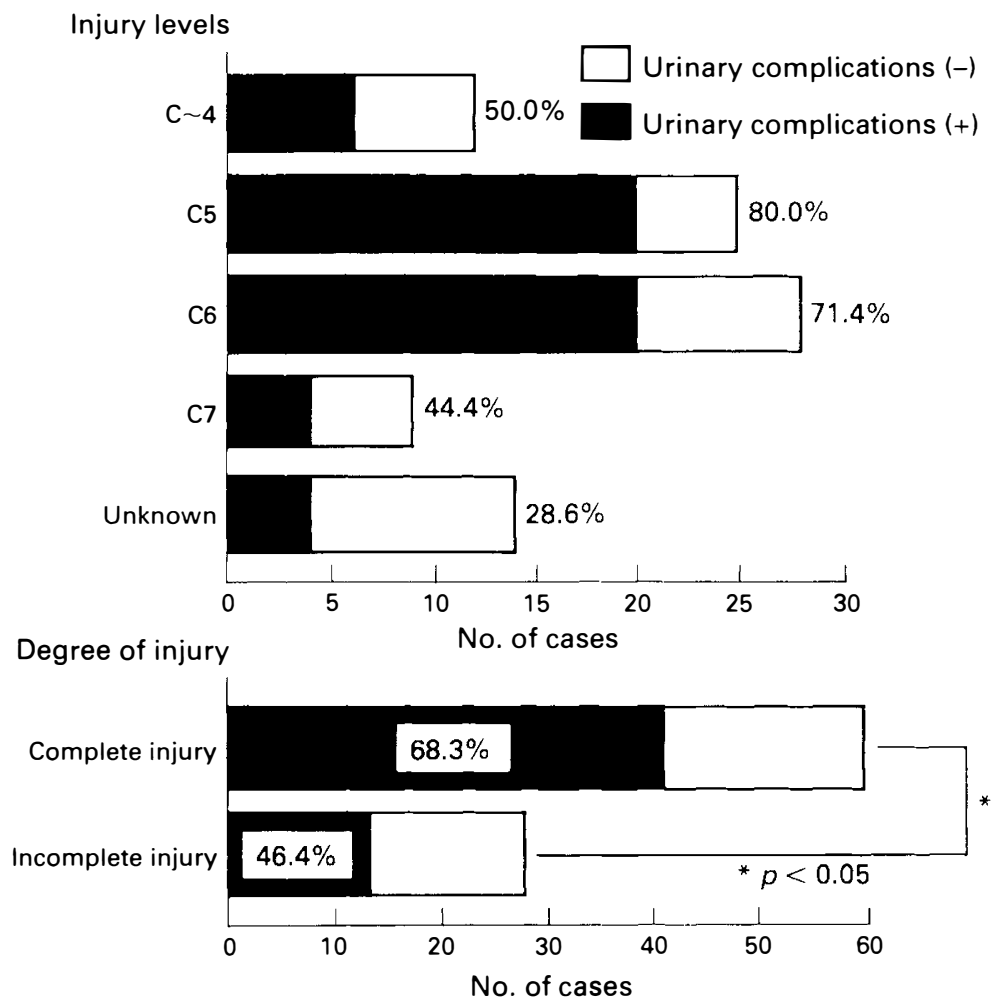

Figure 1 Levels and degrees of injury and incidence of urinary complications.

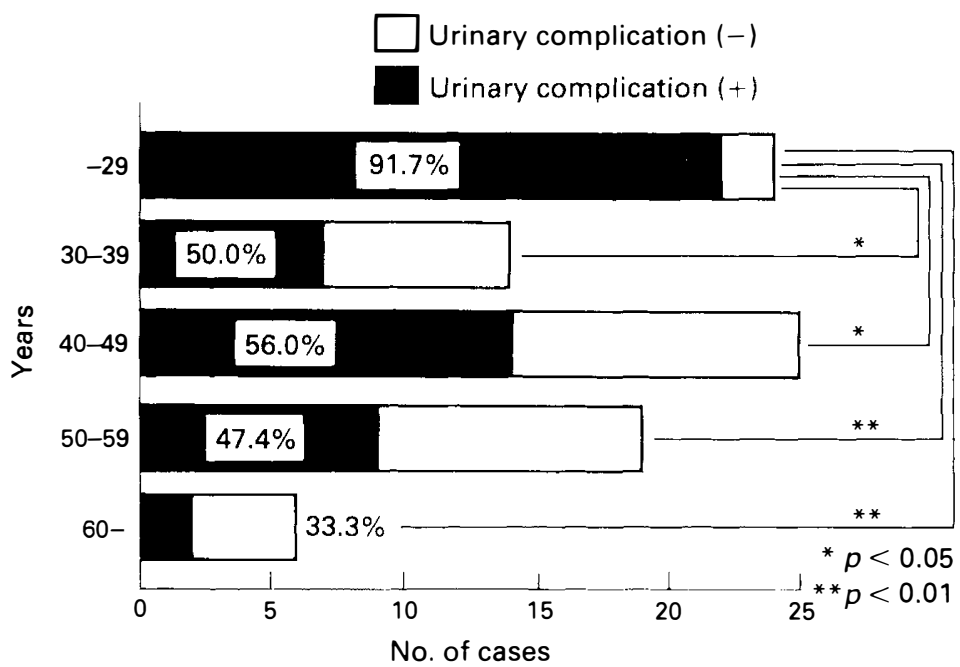

Figure 2 Age of onset of injury and incidence of urinary complications. 


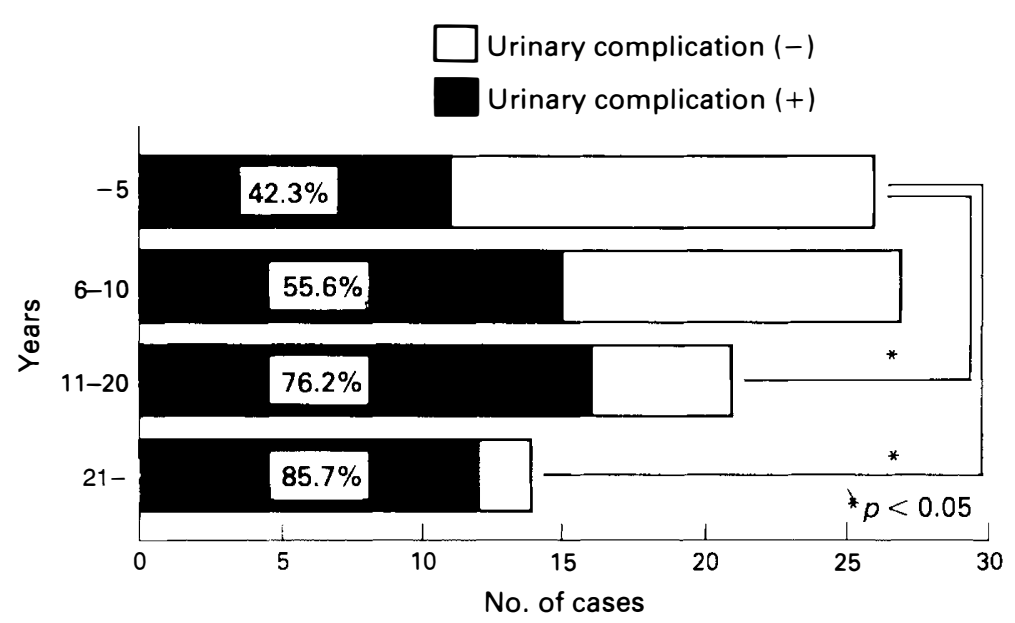

Figure 3 Period after injury and incidence of urinary complications.

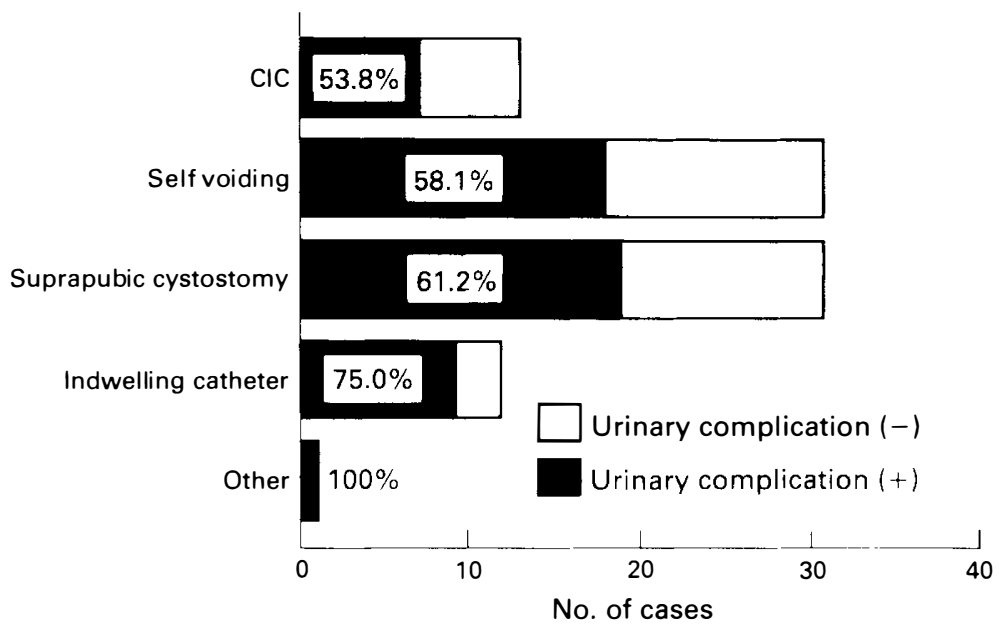

Figure 4 Urinary management and incidence of urinary complications.

III). Although there was no difference in injury levels, the ratio of complete injury patients was higher in the groups with a greater number of complications (group I: $55.9 \%$, group II: $71.9 \%$, group III: $81.8 \%$ ). Also, the mean age of onset was younger and the mean period after injury was longer in the groups with more complications. Regarding urinary management, it was characteristic that the rate of patients managed by an indwelling catheter was high in group III, whereas in the other groups, the rate of cases with self voiding was high.

\section{Discussion}

With the improvement of urinary management, the incidence of death in SCI patients with urinary dysfunction has decreased. ${ }^{1,2}$ However, urinary complications such as urinary stones, urinary tract infections, vesicoureteral reflux and hydronephrosis are still some of the most common complications and many authors stress the importance of adequate urinary management from the early stage of injury. ${ }^{3,4}$ Among all levels of injury, cervical cord injury patients 

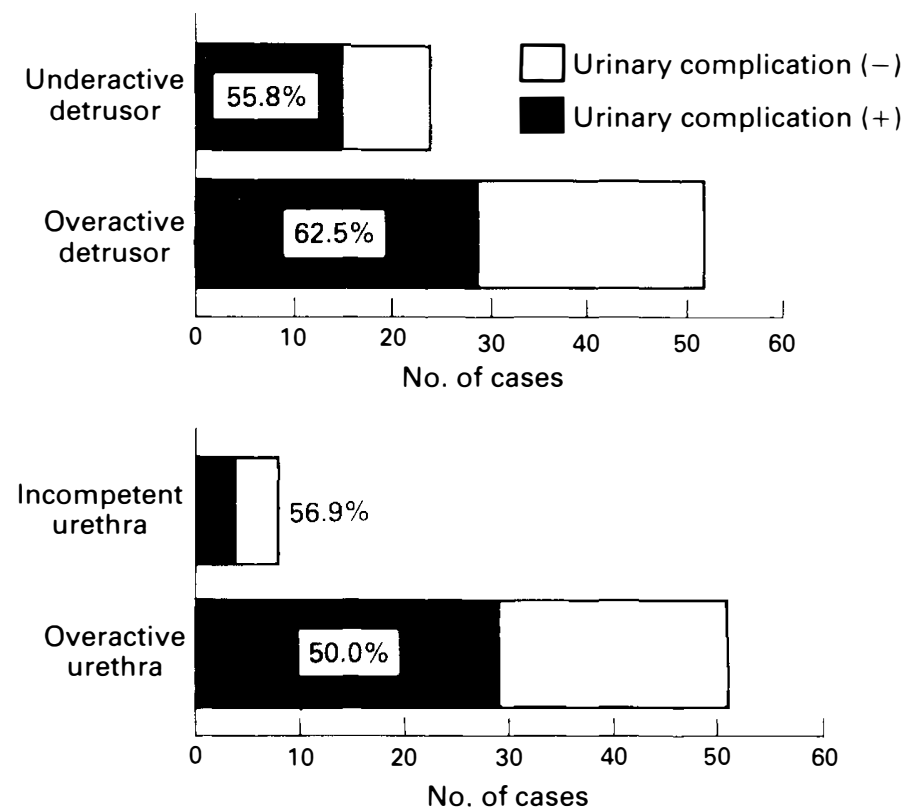

Figure 5 Urodynamic findings and incidence of urinary complications.

Table III Numbers of urinary complications and other factors

\begin{tabular}{|c|c|c|c|}
\hline & Group I & $\begin{array}{l}\text { Group II } \\
\text { No. (\%) }\end{array}$ & Group III \\
\hline Injury levels & 34 & 32 & 22 \\
\hline$C \sim 4$ & $6 \quad(17.6)$ & $4 \quad(12.5)$ & $(9.1)$ \\
\hline C5 & $5 \quad(14.7)$ & $10 \quad(31.3)$ & 10 \\
\hline C6 & $8 \quad(23.5)$ & $13(40.6)$ & $7 \quad(31.8)$ \\
\hline $\mathrm{C} 7$ & $5 \quad(14.7)$ & $3 \quad(9.4)$ & $1 \quad(4.5)$ \\
\hline Unknown & $10 \quad(29.4)$ & $(6.3)$ & $(9.1)$ \\
\hline \multicolumn{4}{|l|}{ Degrees of injury } \\
\hline Complete/incomplete & $19 / 15$ & $23 / 9$ & $18 / 4$ \\
\hline Mean age of onset & 45.7 & 38.7 & 34.1 \\
\hline Mean period after onset & 8.0 & 12.0 & 16.5 \\
\hline \multicolumn{4}{|l|}{ Urinary management } \\
\hline $\mathrm{CIC}$ & $3 \quad(8.8)$ & $3 \quad(9.4)$ & $(4.5)$ \\
\hline Self voiding & $16(47.1)$ & $15 \quad(46.9)$ & $6(27.3)$ \\
\hline Suprapubic cystostomy & $12 \quad(35.3)$ & $12 \quad(37.5)$ & $7 \quad(31.8)$ \\
\hline Indwelling catheter & $3(8.8)$ & $2(6.3)$ & $7 \quad(31.8)$ \\
\hline Other & $0 \quad(0)$ & (0) & $1 \quad(4.5)$ \\
\hline
\end{tabular}

Group I: no urinary complication; group II: 1-2 urinary complications; group III: more than 3 urinary complications.

especially seem to be at greatest risk for urinary disorders because they have a greater chance of having a higher vesical pressure than those with lower injury levels, as was reported by Herschorn et al.$^{5}$ The fact that tetraplegics cannot use CIC is also an important factor. In our series, patients with levels higher than $\mathrm{C} 4$ showed a lower incidence of urinary complications than did those with C5 and C6 levels. It was probably 
because there were more cases with an incomplete lesion in these levels than in others (C 4: 5/12, C5: 2/25, C6: 9/28, C7: $1 / 9)$ and as Fam et al reported, those with a complete lesion had a higher incidence of urinary tract infection than those with an incomplete lesion. ${ }^{6}$ Also, DeVivo ${ }^{7}$ reported that spinal cord injury patients in whom renal calculi developed were more likely to be those who had complete lesions. In our cases $68.3 \%$ of those with a complete lesion and $46.4 \%$ of those with an incomplete lesion had urinary complications.

At the age of onset, there was a significantly higher incidence of urinary complications in those younger than 29 years of age. The reasons for this were considered to be that the ratio of complete injury patients was extremely high in the youngest age group (0-29 yrs: $91.7 \%, 30-39$ yrs: $64.3 \%$, 40-49 yrs: $64.0 \%, 50-59$ yrs: $68.4 \%, 60$ yrs-: $0 \%)$. In relatively younger age groups $(<49$ years), the mean duration periods after injury were longer than in older age groups ( $>50$ years), and those with a longer duration had more urinary complications.

As many authors have previously reported, $4.8 \mathrm{CIC}$ is an excellent method of urinary management to prevent urinary complications in spinal cord injury patients. But this cannot be indicated for all cervical injury patients because of the functional disorder of the upper exremities and/or poor ADL. For these cases, self voiding with low vesical pressure should be directed and for those who cannot void under low pressure because of DSD, other urinary management using a catheter (suprapubic cystostomy or indwelling catheter) might be inevitable.

Gerridzen et al noted that risk factors for upper tract deterioration were high detrusor pressure during urine storage in those with an areflexic bladder and during voiding in those with hyperreflexic bladder and DSD. ${ }^{9.10}$ Although we could not find any urodynamic differences in our cases based on the incidence of urinary complications, it is needless to indicate the importance of low pressure voiding.

From our results, there were some risk factors affecting urinary complications ie complete injury, younger age of onset than 29 years, longer period after injury, and urinary management by catheterisation. In treating these patients we should pay special attention to the prevention of urinary complications. Also we should seek for signs of urinary abnormalities at an early stage by close follow up, using periodical radiographic examinations, urinalysis, blood chemistry etc. If necessary, we should modify urinary management so as to obtain the optimum one as soon as possible.

\section{References}

1 Hackler RH (1977) A 25-year prospective mortality study in the spinal cord injured patient: comparison with the long-term living paraplegic. J Urol 117: 486-488.

2 Jackson AB, DeVivo MJ (1992) Urological long-term follow-up in women with spinal cord injuries. Arch Phy's Med Rehabil 73: 1029-1035.

3 Yasuda K, Hattori T, Murayama N, Yamashiro Y. Shimazaki J, Namiki T et al (1984) Long term follow-up results of different urinary management during the acute phase of cervical cord injury patients. Jpn $J$ Urol 85: $1896-1902$.

4 Iwatsubo E, Uozumi J, Ando S (1989) Results of acute urinary management of spinal cord injuryindwelling catheter versus intermittent catheterization. JJTOM 7: 14-18.

5 Herschorn S. Barkin M, Comisarow RH (1982) Value of urodynamic studies in the management of acute spinal cord injury. In: Tator $\mathrm{CH}$, editor. Early Management of Acute Spinal Cord Injury. Raven Press, New York: 279.

6 Fam BA, Rossier AB, Blunt K, Gabilondo FB, Sarkarati M, Sathi J et al (1978) Experience in the urologic management of 120 early spinal cord injury patients. J Urol 119: 485-487.

7 DeVivo MJ, Fine PR. Cutter GR, Maetz HM (1984) The risk of renal-calculi in spinal cord injury patients. J Urol 131: 857-860.

8 Jacobs SC, Kaufman JM (1978) Complications of permanent bladder catheter drainage in spinal cord injury patients. J Urol 119: 740-741.

9 Gerridzen RG, Thijssen AM, Dehoux E (1992) Risk factors for upper tract deterioration in chronic spinal cord injury patients. J Urol 147: 416-418.

10 Staskin DR (1991) Hydroureteronephrosis after spinal cord injury: Effects of lower urinary tract dysfunction on upper tract anatomy. Urol Clin North Am 18: 309-316. 